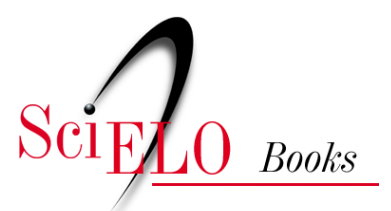

\title{
Histórias do Dr. Zilton Andrade (maio de 1999)
}

\author{
Virgínia Schall
}

\section{SciELO Books / SciELO Livros / SciELO Libros}

SCHALL, V. Histórias do Dr. Zilton Andrade (maio de 1999). In: Contos de Fatos: histórias de Manguinhos [online]. Rio de Janeiro: Editora FIOCRUZ, 2001, pp. 109-124. ISBN: 978-85-7541614-3. Available from: doi: 10.7476/9788575416143.0011. Also available in ePUB from: http://books.scielo.org/id/hdq6f/epub/schall-9788575416143.epub.

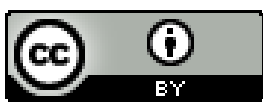

All the contents of this work, except where otherwise noted, is licensed under a Creative Commons Attribution $\underline{4.0 \text { International license. }}$

Todo o conteúdo deste trabalho, exceto quando houver ressalva, é publicado sob a licença Creative Commons Atribição 4.0. 


\section{Histórias do Dr. \\ Zilton Andrade \\ (maio de 1999)}

O homem se agita e Deus o conduz. ${ }^{28}$

1 a de 1999. Viajei até Salvador para levar alguns moluscos fixados animais por transporte aéreo, mas queria também conversar com o pesquisador sobre algumas histórias que ele me contara informalmente, durante um jantar em Ouro Preto, por ocasião de um encontro sobre esquistossomose. Eu já o admirava ao vê-lo apresentar os seus trabalhos, sempre tão seguro e tranqüilo, um ar sereno e um domínio amplo sobre a sua área de pesquisa, a patologia. Eram apresentações impecáveis, do ponto de vista tanto da metodologia científica quanto dos meios de comunicação empregados: slides sempre muito bem feitos, tempo cronometrado, fala clara, dicção perfeita, o que torna compreensível o mais difícil conteúdo.

Durante o jantar daquela noite, minha admiração cresceu e consolidou a imagem de uma pessoa afável, culta, com quem a conversa faz o tempo ser pequeno. A vontade que dá é de permanecer ali, escutando, perguntando, aprendendo, deliciando-se com a sua sabedoria. Desde aquela noite, combinamos que eu e a Dra. Cecília Pereira de Sousa (especialista em

\footnotetext{
${ }^{28}$ Citado pelo Dr. Zilton no decorrer da nossa conversa, como um dito popular que ilustra o caminho de sua pesquisa recente, relatado adiante.
} 
malacologia do $\mathrm{CP}$. $\mathrm{RR}$ ) enviaríamos os animais preparados para o trabalho de histoquímica, relacionado ao moluscicida vegetal, o látex da planta coroade-cristo, para um trabalho em colaboração com o Dr. Zilton. Aproveitei a deixa e também solicitei a ele que me concedesse uma entrevista mais detalhada sobre as histórias, com o que concordou, desde que agendássemos a data.

Agora era chegado o dia da entrevista e eu tomei o avião cheia de expectativa. Foi um dia maravilhoso. O sol brilhava em Salvador, após semanas de chuva intensa, até mesmo catastrófica, que deixou muitos desabrigados, como sempre acontece no nosso Brasil, onde os flagelos se repetem idênticos, de norte a sul, a merecer maior atenção do poder público. A temperatura era amena e a alameda de bambus no caminho do aeroporto para a cidade parecia uma galeria verdejante, uma belíssima e natural porta de entrada na capital da Bahia. Como cheguei perto da hora do almoço, depois de entregar a caixa de isopor contendo os moluscos fui apresentada pelo Dr. Zilton a sua esposa, Sônia, também pesquisadora, e eles me levaram para um restaurante à beira-mar. Surpreendi-me com a beleza e a remodelação da cidade. Havia muitos anos que eu não visitava Salvador e foi uma satisfação vê-la tão linda e bem cuidada. O restaurante típico, de atendimento perfeito, a culinária baiana fervilhando na mesa, espalhando o cheiro e o sabor aromático dos frutos do mar temperados com dendê: nada mais apetitoso e perfeito. Brindada com a conversa do casal, ali mesmo eu já poderia ter registrado muitas outras histórias, não apenas de temas científicos mas também de culinária, as quais certamente resultariam em um livro de deixar água na boca.

Após o almoço, a tarde transcorreu lá fora sem que percebêssemos, e eu era só ouvidos na sala do Dr. Zilton, onde pude registrar algumas das suas histórias. Então, silêncio, espero fazer ouvir a sua voz serena nas próximas páginas. 


\section{Dr. Zilton Reconta uma História de Pasteur}

Esta história está contada no livro de Paul de Kuif intitulado Casadores de Micróbios, um best-seller da década de $30 .{ }^{29}$ Certa vez, o cientista francês Louis Pasteur chamou um auxiliar e solicitou uma cultura de uma bactéria que ele estava estudando e que era causadora da cólera de galinhas. Após inocular as bactérias nas galinhas, ele ficou surpreso quando verificou que a cultura não estava matando as aves, e procurou saber por quê. Percebeu que as culturas já estavam há muito ali armazenadas, pois o seu auxiliar não as havia repicado, prevendo que não haveria novas inoculações antes das férias. Pasteur ficou bastante decepcionado com o seu auxiliar, considerando-o relapso por ter deixado as culturas envelhecerem no laboratório. Mandou jogar tudo fora e saiu de férias. Quando voltou das férias, solicitou culturas novas, as quais foram preparadas, apresentando-se ativas e virulentas. Inoculou as culturas recém-preparadas em galinhas novas no laboratório. Como as galinhas anteriores, inoculadas com as culturas velhas, ainda estavam no biotério, Pasteur decidiu injetar as novas culturas nestas aves remanescentes e que não haviam apresentado efeito algum ao receberem as bactérias da vez anterior. Passados alguns dias, ele obteve então um surpreendente resultado: todas as galinhas que receberam as bactérias da cultura nova pela primeira vez morreram, ao passo que as aves nas quais havia sido injetada a cultura anterior permaneceram vivas. Pasteur raciocinou e verificou que a cultura envelhecida tivera o poder de proteger as galinhas contra a inoculação de uma cultura virulenta. A partir de então, ele começou a investigar esse território e chegou à descoberta de formas importantes de vacinação.

Esse experimento - no qual Pasteur utilizou como vacina culturas envelhecidas que tinham perdido o seu poder patogênico e que, no entanto,

\footnotetext{
${ }^{29}$ Este livro foi apontado pelo Dr. Albert Sabin como a grande influência em sua decisão de abraçar a carreira de pesquisador. N. A.
} 
mantinham o poder de sensibilizar e de vacinar essas aves - foi o primeiro passo dado na direção da descoberta da vacina. A vacina, com este nome, havia sido descoberta por Jansen ao estudar a varíola. No caso de Pasteur, ele descobriu que uma das formas de se fazer tal proteção poderia ser também o uso de culturas envelhecidas ou mortas. A partir da evidência de proteção com as culturas envelhecidas, ele pesquisou culturas mortas pelo calor, pelo fenol, pelo formol e, assim, desenvolveu uma série de demonstrações de que um primeiro contato com a bactéria atenuada em sua infecciosidade poderia proteger o animal recipiente contra uma outra injeção da mesma bactéria virulenta. Isso revolucionou completamente a medicina e gerou novos avanços, como a descoberta de que mesmo injeções de toxinas já eram capazes de estimular a proteção, não havendo nem mesmo necessidade de que estas fossem o corpo bacteriano, mas apenas as toxinas por elas produzidas. E assim, houve - a partir daquele erro inicial de laboratório, que segundo conta Paul de Kuif, teria originado um acesso de cólera no Pasteur contra o seu auxiliar, acusado de ter negligenciado as suas funções - uma explosão no conhecimento e na tecnologia. A negligência, percebida e analisada por um pesquisador observador e experiente, acabou por favorecer a ciência.

\section{Dr. Zilton Conta sua Própria História}

No intuito de colaborar com o seu livro, eu diria que aconteceram várias situações que conduziram o meu interesse pelo problema da reversibilidade da fibrose. Durante todo o meu curso médico e mesmo depois de formado, eu tinha uma noção de que uma fibrose cicatricial era uma acontecimento irreversível. As cicatrizes, como os diamantes, seriam para sempre. Essa era uma idéia sustentada por muita gente.

Tempos atrás, se não me engano, nos anos 60, Naftale Katz e Zigman Brener publicaram um relato sobre uma visita a uns portadores de 
esquistossomose que haviam sido examinados cerca de dez anos antes. Eles verificaram que alguns desses pacientes, portadores da forma hepatoesplênica no passado, forma esta que cursa com muita fibrose hepática, já não a apresentavam mais: ela havia desaparecido espontaneamente, sem qualquer tratamento. Esse trabalho foi discutido entre as pessoas que se interessavam pela esquistossomose, e a explicação mais provável era que teria havido um erro de diagnóstico ou de avaliação, porque a fibrose não poderia ter desaparecido assim, ainda mais espontaneamente. Esse dado ficou como um dado estranho e eu me lembro de ter discutido o assunto com alguns colegas, aqui na Bahia.

Esse fato sempre ficou como uma questão para mim, até que surgiu uma oportunidade de investigá-lo. Eu tenho um colega e amigo francês, que se chama Jean-Alexis Grimaud. Ele esteve no Brasil por dois anos, fazendo o seu serviço militar, e, como médico, passou por um estágio aqui no laboratório, quando nós fizemos uma boa amizade. Depois ele voltou para a França, trabalhando como um dos líderes de pesquisa no Instituto Pasteur de Lyon. Ele desenvolveu anticorpos que podiam caracterizar tipos genéticos de colágeno. E então dispunha desses anticorpos no momento em que havia uma noção de que existia um colágeno facilmente reversível, chamado colágeno de tipo III. Existia um outro que era definitivo, aquele que estava na pele, no tendão, nos ossos, chamado de colágeno de tipo I. Como ele tinha os dois tipos de anticorpos e estava sempre me convidando para ir trabalhar uns meses em Lyon, eu reuni as duas idéias para um projeto em colaboração. A questão era: vamos ver na esquistossomose tratada o desaparecimento da fibrose e verificar qual é o colágeno que predomina e por que a fibrose recente desaparece com o tratamento. Então nós infectamos animais durante oito semanas e ao final desse tempo foi feito um tratamento nos animais. Em seguida, passamos a examiná-los a cada 15 dias. Realmente, a fibrose, essa fibrose recente, começava a desaparecer de um modo relativamente rápido. A nossa surpresa foi que tanto o colágeno do tipo I como o colágeno do tipo III estavam presentes nos granulomas. 
Embora o tipo III (mais reversível) predominasse, verificamos que o desaparecimento dos dois tipos era simultâneo. Quando só restava uma pequena porção de tecido fibroso, o tipo III e o I estavam presentes, não havia uma preferência na reabsorção. Isso nos pareceu interessante e nos estimulou a entrar na área de estudo da fibrose.

Depois resolvemos examinar o desaparecimento da fibrose na esquistossomose mais crônica. Tínhamos animais com 25 semanas de infecção, nos quais podia-se encontrar a fibrose dos granulomas antigos e, nesses casos, a literatura a considerava irreversível, o que era tacitamente aceito por todos. Verificamos que a fibrose antiga desaparece muito mais lentamente que a recente, mas não é irreversível. Enquanto a fibrose recente desaparecia em torno de um mês ou dois, a fibrose antiga aparentemente não se modificava durante este tempo. Mas, tivemos um pouco de paciência e esperamos quatro meses. Depois desse tempo, havia evidências nítidas de que a fibrose antiga estava desaparecendo. Com mais tempo ainda, ela desaparecia quase totalmente.

Depois de verificarmos que não era o tipo genético de colágeno predominante que fazia a diferença na reabsorção da fibrose, recente e antiga, voltamo-nos para o estudo com a microscopia eletrônica, a qual, em Lyon, é da mais alta qualidade. Verificamos então que quando havia desaparecimento da fibrose recente, existia um quadro ultra-estrutural característico. Com a fibrose antiga, o quadro era completamente diferente. Em patologia existe uma noção de que, toda vez que você tem morfologia diferente, a função também é diferente, e vice-versa. A estrutura de um rim é diferente da do fígado, os quais têm funções distintas. Mas até mesmo numa célula que a gente encontre na hipófise, por exemplo, onde há três tipos de células, a gente sabe que a função delas é diferente. Função e forma andam juntas. Então, deduzimos que o processo de destruição da fibrose antiga talvez não fosse exatamente o mesmo que destrói a fibrose recente.

Com base nessa conclusão, a de que há dois tipos de degradação de colágeno, iniciamos vários estudos. Surpreendemo-nos nos perguntando 
o seguinte: por que esse aspecto passou despercebido durante tanto tempo? Pelo seguinte fato: a fibrose antiga precisa de um modelo experimental que requer uns quatro meses para sua formação e de um período de espera de outros quatro ou seis meses para se verificar a sua regressão. Nos laboratórios, são poucos os grupos que fazem pesquisas com uma espera tão longa assim, enquanto os animais ficam 'guardados', comendo e bebendo no biotério. Verificamos que os modelos que são utilizados para estudar a degradação do colágeno, por meio dos quais aprendemos tudo o que sabemos sobre morfologia, bioquímica, colagenases, citocinas etc., são todos modelos 'agudos', isto é, nos quais a fibrose desaparece em poucos dias. A fibrólise da involução da cauda do girino, por exemplo, leva poucos dias ou algumas horas. A involução do útero grávido da rata, que é um outro modelo, leva 24 horas. Existe um modelo chamado de granuloma da carragenina, que é uma substância extraída de uma planta marinha. Injetando-se essa substância em, por exemplo, um tecido subcutâneo ou dentro do fígado mesmo, provoca-se um foco de necrose hemorrágica seguido da formação de uma fibrose muito intensa em torno, mas que, em 26 ou 28 dias, no mais tardar, desaparece completamente. A força que estava estimulando a fibrogênese como que se exaure, e o organismo faz a reabsorção, a ponto de, caso você demore muito a analisá-la, tornar-se impossível localizá-la, assim como o ponto onde foi injetada a carragenina. Como se vê, são todos modelos agudos, de duração rápida. A ultra-estrutura desses modelos é exatamente igual à que se vê na esquistossomose aguda em regressão. Mas na fibrose antiga, a degradação que se segue à retirada da causa tem uma ultra-estrutura diferente, e essa não havia ainda sido descrita. Ela está presente em outros modelos além da esquistossomose. Estamos tentando verificar que fatores permanecem ou fazem parte dessa degradação. Para a reabsorção rápida, os vários fatores já estão bem claros. A reabsorção do colágeno recente é intermediada por estímulo dos fibroblastos ou de outras células para que secretem as metaloproteinases, 
que são enzimas que degradam o colágeno, chamadas também de colagenases. Sabemos que, quando o colágeno permanece no local, estabelecem-se pontes, que são chamadas de cosslinkings. São pontes de lisina, intra e intermoleculares, que reticulam e reforçam o colágeno, ou seja, amadurecem o colágeno. E estas pontes de lisina são pontes que ocupam exatamente os sítios onde a colagenase poderia atuar. É possível que a natureza recorra a outro tipo de degradação que não a colagenase, para fazer esta destruição e reabsorção.

Um exemplo dessa degradação espontânea foi demonstrado pelo Dr. Bina aqui na Bahia, em Taquaratinga, onde ele conseguiu interromper a transmissão da esquistossomose alguns anos atrás. Ele mobilizou a população, usou muito moluscicida, tratou todos os pacientes na região, a qual é isolada, e assim fez desaparecer completamente a transmissão da esquistossomose. Passados alguns anos, as formas hepatoesplênicas regrediram em alguns indivíduos, e estes melhoraram. Ele mostrou que a contínua reinfecção é importante para a evolução das formas graves. Quando ocorreu a interrupção da transmissão da doença, os indivíduos foram tratados e o quadro hepatoesplênico involuiu mais rapidamente. Assim, o que o Naftale e o Brener observaram anos atrás sobre a involução espontânea foi confirmado e mostrou-se que, com o tratamento, a involução é ainda mais rápida e evidente. Então, começou-se a verificar em várias partes do mundo - no Brasil, no Sudão etc. - que a fibrose hepática da esquistossomose hepatoesplênica, agora analisada por meio da ultrasonografia, um método não invasivo, pode regredir. Assim, a esquistossomose passou a ser a primeira doença humana em que se demonstra de maneira inequívoca uma degradação e uma reabsorção da fibrose em larga escala. Alguns reumatologistas já haviam demonstrado que, às vezes, a fibrose das articulações podia regredir em pacientes bem tratados, mas sempre em pequena escala. Assim, sabemos agora que qualquer tipo de fibrose é reversível. O que mantém a fibrose é o estímulo constante: se o estímulo continuar, a fibrose continua. Com o tratamento do paciente com esquistossomose, exterminando-se os vermes e os ovos, que no caso 
são os estímulos, as forças de degradação do tecido fibroso predominam sobre as forças de sua formação.

Acredita-se que no organismo humano, em condições normais, o tecido fibroso está se formando e sendo reabsorvido ao mesmo tempo, mas o organismo mantém um equilíbrio estroma-parênquima. Com o tratamento para a esquistossomose, por exemplo, tem-se verificado que é preciso algo em torno de dois anos ou mais para que seja notada a reabsorção da fibrose. Há pesquisadores que observaram casos de fibrose em indivíduos com a forma hepatoesplênica de instalação recente, pessoas só com 16 ou 18 anos de idade, nas quais a reabsorção acontece em menor tempo, cerca de seis meses. Agora, aqueles indivíduos de quarenta, cinqüenta anos de idade com fibrose hepatoesplênica esquistossomótica requerem maior tempo para que a reabsorção seja observada. Posso the citar um caso de uma pesquisa feita com recursos da OMS, em que um pesquisador tratou indivíduos e seis meses depois disse não ter observado regressão da fibrose. Mas o Dr. Kenneth Mott, já falecido, naquela época coordenador do programa de esquistossomose na OMS, veio ao Rio de Janeiro para o Simpósio Internacional de Esquistossomose e tomou conhecimento desses trabalhos que estou relatando aqui. Recomendou então ao pesquisador que o tempo de observação deveria ser aumentado. Dois anos depois, a regressão da fibrose estava confirmada.

Aí há uma grande avenida para estudos, para verificar quais são os fatores que atuam na degradação crônica da matriz extracelular. Não é um estudo fácil, porque exige um modelo crônico e uma sofisticação de pesquisa que nós não temos. Mas, eu tive recentemente uma ajuda inesperada. Recebi uma carta de um colega argentino, o Dr. Daniel Gomez, dizendo que ele estava interessado na degradação do colágeno. Ele havia passado cinco anos no Instituto Nacional de Câncer nos Estados Unidos - interessado nas colagenases, porque a neoplasia maligna, para gerar as metástases, utiliza uma produção de colagenase que rompe o tecido conjuntivo para que as células penetrem e mudem de lugar, migrando. Ele estudava esses aspectos e encontrou na literatura os nossos trabalhos sobre esquistossomose. $\mathrm{Na}$ 
carta, o Dr. Gomez mencionou a Fundação Antorchas em Buenos Aires, que estava financiando a colaboração entre pesquisadores brasileiros e argentinos. Perguntava ainda se eu não gostaria de iniciar uma pesquisa conjunta. Achei que a oferta dele tinha caído do céu. Nos correspondemos, nos visitamos mutuamente, e agora o nosso primeiro trabalho acaba de sair (American Journal of Tropical Medicine and Hygiene, jul.1999). Verificamos que não havia expressão de colagenases ou TIMP na fibrose portal de portadores da forma hepatoesplênica da esquistossomose, mas que estes fatores se expressavam intensamente quando os granulomas periovulares apareciam neste mesmo tecido portal. Foi um achado interessante, embora não seja um dado definitivo, porque naqueles locais de degradação crônica pode estar havendo colagenase em uma quantidade tão pequena que o método de imunohistoquímica ainda não seja capaz de detectá-la, mas que talvez pudesse ser detectada pela imunoeletromicroscopia. De qualquer maneira, nós mostramos, lado a lado, uma degradação aguda do granuloma e uma degradação crônica, e que, além do aspecto ultra-estrutural, existe uma diferença imunohistoquímica no que diz respeito à expressão de metaloproteinases entre os dois tipos de degradação: a aguda e a crônica. Na fibrose crônica, o colágeno está sendo degradado em pequenos focos, como foi possível identificar na ultra-estrutura. Alguma coisa faz com que aquele foco ali degrade, e não o outro, vizinho, que nada sofre ainda. Então alguma coisa se expressou e é como se, pouco a pouco, estivesse tirando um pouquinho ali, um pouco lá, e vai lentamente. Nós sabemos que em indivíduos tratados, com o passar do tempo às vezes uma grande quantidade de colágeno é removida por meio desse expediente. Então o que está acontecendo ali? Na degradação aguda, em toda parte você vê a fragmentação do colágeno, ele se fragmenta em pedaços de diferentes tamanhos, de calibres diferentes, ele se mistura. $\mathrm{Na}$ crônica, não: você observa vastas áreas de tecido fibroso e às vezes acha um foco, onde está começando uma degradação. O que faz esta área começar a degradação e a sua vizinha não? Esta é uma pergunta a que ainda estamos buscando responder. 
Mas o que eu queria ilustrar com esta conversa, para colaborar com o seu livro, cuja idéia eu acho muito original, é que um acontecimento começa e, como dizem, o homem se agita e Deus o conduz, e vai se encaminhando para novos rumos. No meu caso, esta pesquisa começa com um relacionamento de interesse comum com uma pessoa que depois mudou de lugar, mas mantivemos o contato científico, e isso nos deu a possibilidade de desenvolver estudos que a princípio não tinham nada a ver com esse final - a colaboração com o pesquisador da Argentina. Esta parte final ilustra um detalhe que tenho mostrado aos meus alunos: digo sempre que o indivíduo que pesquisa está emitindo sinais. Estes podem ser captados à distância, às vezes não são captados pelo vizinho que está ao lado. Mas isto é que é a parte interessante da ciência: é justamente haver um outro indivíduo, não importa de onde seja, que está interessado no mesmo tema, percebe a possibilidade de colaboração e, mais ainda, surge uma entidade que está disposta a financiar associações entre pesquisadores de diferentes países, como essa promovida pela Fundação Antorchas, entre brasileiros e argentinos. E, assim, as coisas se ajustam, o trabalho toma novo rumo, possibilitando aventuras científicas, as quais resultam em dados que a princípio podem ser modestos, mas que deixam sempre a estimulante perspectiva de, de alguma maneira, virem a contribuir para o progresso da ciência.

\section{Um Pouco da História do Centro de Pesquisas Gonçalo Muniz}

Durante o governo de Otávio Mangabeiras, que estava no governo da Bahia logo que terminou a ditadura de Getúlio Vargas, foi criado um centro de pesquisas aqui em Salvador. O centro pertencia ao estado e a princípio chamava-se Instituto Oswaldo Cruz. Logo depois seu nome mudou para Instituto de Saúde Pública. Para mantê-lo, Otávio Mangabeira destinoulhe umas apólices e, com o dinheiro delas, criou uma fundação que se 
chamava Fundação Gonçalo Muniz, em homenagem a um professor de patologia geral da Faculdade de Medicina da Bahia. Essa fundação sofreu muitos problemas de recursos e acabou, não foi muito adiante. Em seu lugar foi criado o Laboratório Central do Estado, conhecido como Lacen, que permanece, é hoje nosso vizinho aqui. Trata-se de um laboratório de diagnóstico em saúde pública que prioriza os serviços, e ñão a pesquisa.

Mas, voltando ao primeiro instituto: quando ele foi criado, tinha por missão prestar serviços de laboratório ao estado e, 'ao mesmo tempo, incentivar a pesquisa científica na Bahia e formar pesquisadores. Inicialmente foram montados dois cursos, chamados de cursos de formação técnica e científica, ministrados pelos melhores professores daquele tempo no Brasil. Eu era estudante de medicina na época e fiz o curso com vários colegas. Para você ter uma idéia do nível de excelência dos professores, nós tivemos aulas, por exemplo, com o Prof. Samuel Pessoa, com o Prof. Herman Lent, o Prof. Hugo de Souza Lopes, o Prof. Otto Bier e vários outros que vieram do Rio e de São Paulo para dar o curso. Dr. Lacaz foi outro que também veio, foi excelente. Após esses cursos, algumas pessoas foram contratadas para trabalhar, como foi o meu caso. Imediatamente após a contratação, eu também fui contemplado com uma bolsa de estudos para viajar para o exterior e passei dois anos fazendo a minha residência na Faculdade de Medicina da Universidade de Tulane em Nova Orleans, EUA.

Mas, voltando à Fundação Gonçalo Muniz: naquela época, veio para dirigi-la o Prof. Aluízio Prata, que logo comprou um terreno, que é este aqui, onde estamos. Ele sabia que o lugar havia sido utilizado por um laboratório farmacêutico chamado Cedar, feito aqui na Bahia aparentemente com verba da Alemanha, destinado a produzir quinina para as tropas alemãs. O laboratório tinha caldeiras e uma série de outras coisas; suas instalações funcionavam aqui no bairro de Brotas, que era um bairro mais ou menos deserto na época, aqui nesta região. Isto acabou se tornando uma propriedade do estado. Depois da guerra, o estado da Bahia desapropriou o terreno dos alemães e ficou tomando conta desta área, que não estava 
servindo para nada. Então, o Prof. Aluízio Prata solicitou permissão para instalar aqui um biotério para manter animais de laboratório, e os pesquisadores acabaram vindo também para cá. Na época, tinha um grupo francês que veio trabalhar aqui. Era um grupo originário do Prof. André Capron, que trouxe equipamentos e se estabeleceu no prédio antigo, aqui nesta área onde está hoje o Centro de Pesquisas.

Posteriormente, esta área, que era do estado, foi desativada. Aí surgiu a idéia, na Fiocruz, cujo presidente na época era o Vinícius, ${ }^{30}$ de utilizá-la para fazer um centro de pesquisas, uma unidade da Fiocruz, à semelhança do Centro de Pesquisas René Rachou (CPqRR) e do Aggeu Magalhães (CPqAM), que já existiam, respectivamente, em Belo Horizonte e Recife. Esse plano caminhou no governo do Roberto Santos, então governador da Bahia. Porém, ele mudou de idéia, e como o estado estava precisando de dinheiro, decidiu vender isto aqui para imobiliárias, para construção de prédios residenciais. Se a área tivesse sido colocada à venda, teria sido imediatamente comercializada, pois este tornou-se um bairro muito bom e muito valorizado. Mas, na época, estávamos em pleno período militar, e o governador já nomeado para o próximo mandato era o Antônio Carlos Magalhães. Este colocou uma nota no jornal dizendo que se alguém comprasse esta área ele iria desapropriá-la imediatamente, assim que assumisse o governo, porque ela estava destinada a sediar um centro de pesquisas.

Quando o Antônio Carlos assumiu o governo, era presidente da Fiocruz - Dr. Guilardo Martins, ${ }^{31}$ que veio a Salvador e acertou um acordo com o governo. As circunstâncias eram muito boas na ocasião. O secretário estadual de Saúde, Dr. Jorge Nouís, havia sido professor de fisiologia da Faculdade de Medicina e mestre do reitor da Universidade da Bahia, Dr. Marcelo Costa. Assim, o governo e a universidade estavam bem unidas aqui, e a

\footnotetext{
${ }^{30}$ Dr. Vinícius da Fonseca foi presidente da Fiocruz no período de 21/08/1975 a 15/03/1979.

${ }^{31}$ Dr. Guilardo Martins Alves foi presidente da Fiocruz de 15/9/1979 a 02/05/1985.
} 
Fiocruz veio e encontrou esse ambiente favorável. Para fazer o Centro de Pesquisas, havia necessidade de quadros. Eles já pensavam em transferir um pesquisador que tinha um núcleo que restou do antigo instituto, chamado Núcleo de Pesquisa do Sesp (Serviço de Saúde Pública). Dr. Ítalo Sherlock era um pesquisador que fazia entomologia, e seu grupo era pequeno para preencher o centro de pesquisas. Eles precisavam de mais pesquisadores. Como pertencia ao Conselho Científico da Fiocruz, em uma reunião, no Rio de Janeiro, eu, que já havia sido consultado antes pelo Dr. Vinícius, fui novamente sondado pelo Dr. Guilardo, agora sobre a possibilidade de me tornar diretor do centro e de trazer para cá o meu grupo da Faculdade de Medicina. Havia então todo um entrosamento favorável, como eu disse, e seria uma organização que envolveria o governo da Bahia, a universidade e a Fiocruz. O convite veio também numa ocasião importante para o meu grupo. Nós estávamos em condições muito precárias lá na escola de medicina, isso era 1980. Utilizávamos um prédio que a Petrobras havia desocupado no campus da universidade, que era provisório: eles o haviam feito na universidade para ficar de três a cinco anos, apenas enquanto a sede definitiva deles estava sendo construída, e acabaram ficando 13 anos. Então, quando eles saíram, as coisas já estavam muito deterioradas lá, era um prédio de madeira, provisório. Nossas condições de trabalho eram péssimas, o que limitava o próprio desenvolvimento do grupo. Por exemplo: nós havíamos tido uma oferta da Coordenação de Aperfeiçoamento de Pessoal de Nível Superior (Capes) para receber um microscópio eletrônico, e a funcionária que veio nos visitar para planejar a instalação achou que não havia condições adequadas naquele espaço onde estávamos. Nós a trouxemos até aqui e lhe falamos sobre a possibilidade de nos mudarmos para cá. Ela logo afirmou estar plenamente de acordo com a instalação do microscópio aqui, e que daria então o parecer favorável. Esses fatos todos nos estimularam a aceitar o convite e vir para cá. Quando vim, vieram também todos os colegas que estavam envolvidos em atividades de pesquisa do departamento e com o curso de pós-graduação em patologia 
humana. Dessa forma, o centro já nasceu com a pós-graduação aqui dentro, o que foi de grande significado. O nosso compromisso para com a faculdade era o de não nos afastarmos da atividade didática da graduação. Então, todos nós tínhamos tempo integral, com dedicação exclusiva, mas quando chegava 3 e meia, 4 horas, pegávamos o carro e corríamos para a faculdade, para dar aula, e passávamos o resto da tarde lá. Isso nas segundas, quartas e sextas; o resto do tempo era todo dedicado à pesquisa aqui. Naquela época eu já era professor titular da faculdade, mas não era chefe do departamento, e aqui eu me tornei diretor do centro. Fui diretor aqui por dez anos, e quando se iniciou o processo de eleição fui substituído pelo Dr. Moisés Sadigursky, um colega que veio desde o princípio comigo. Depois do Moisés, foi eleito diretor o Mittermayer, ${ }^{32}$ que foi meu aluno, meu orientando, e hoje está fazendo um trabalho extraordinário; ele criou, inclusive, esta área nova onde nós estamos agora, com instalações excelentes. É uma pessoa completamente dedicada à melhoria e ao progresso aqui do Centro de Pesquisas. Foi uma sorte que nós tivemos e ele me parece a pessoa certa no lugar certo.

Durante os dez anos em que fui diretor aqui do centro, nunca saí do laboratório. Eu apenas passava na administração, onde havia um grupo de auxiliares da mais alta confiança e muito eficiente. O grupo administrativo foi nomeado pela Fiocruz, que enviou pessoas do Rio e incluiu uma funcionária daqui, do núcleo anterior. O meu acordo com o Guilardo era de que eu aceitaria ser diretor, mas não poderia largar minhas atividades de pesquisa. O tempo todo, a vida toda, eu fui dedicado à pesquisa, sempre fiz isso, de maneira que assumi a direção como incumbência temporária e a minha atenção era voltada muito mais para o laboratório. Eu tive uma atividade intensa com o pessoal do Tropical Deseases Research (TDR), da OMS, ia quatro, cinco vezes por ano a Genebra para participar dos comitês.

\footnotetext{
${ }^{32}$ Mittermayer Galvão dos Reis, eleito em 1993 e reeleito em 1997, é o atual diretor do Centro de Pesquisas Gonçalo Muniz (CPqGM).
} 
Ia ao Rio para participar das reuniões do Conselho Científico da Fiocruz e queria continuar participando dos congressos científicos da minha área. Desse modo, eu apenas assinava aqui os papéis da diretoria, naturalmente com toda confiança, sabendo das coisas como estavam, mas não tinha uma possibilidade de dar um vôo, vamos dizer assim, para ampliar, ou criar algo novo, se isto me fosse proposto. $\mathrm{Na}$ época não houve nenhuma proposta, pois não havia recursos, era um tempo de restrições de toda ordem - de pessoal, orçamentária etc. -, era o governo do Figueiredo. Mas imagino que, se não tivesse sido assim, se me tivessem oferecido, como ofereceram ao Mittermayer, a possibilidade de ampliar, eu não teria as condições de me dedicar, eu não abdicaria do laboratório, como seria necessário. Assim, a oportunidade de ampliar chegou com o indivíduo certo no lugar certo, que é o Mittermayer. O centro começou em 81, nós estamos agora em 99, são 18 anos dando mostras de que já se consolidou, temos novos pesquisadores chegando, tem havido renovação, ampliação, continuidade e crescimento.

E, complementando o depoimento do Dr. Zilton, ressalto que são diversas as contribuições do Centro de Pesquisas Gonçalo Muniz para a área científica brasileira e internacional, como também para a formação de novos pesquisadores. O centro colabora para o controle, a prevenção de doenças e a promoção da saúde, sobretudo na Bahia. Trata-se, enfim, de uma unidade que colabora para o prestígio e o papel social da Fiocruz no Nordeste e no país como um todo. E, por incrível que pareça, como um mito de origem, o nome primeiro, Instituto Oswaldo Cruz, se fez presente outra vez na instituição, como numa retomada do caminho a que se destina. 


\section{Zilton Andrade ${ }^{33}$}

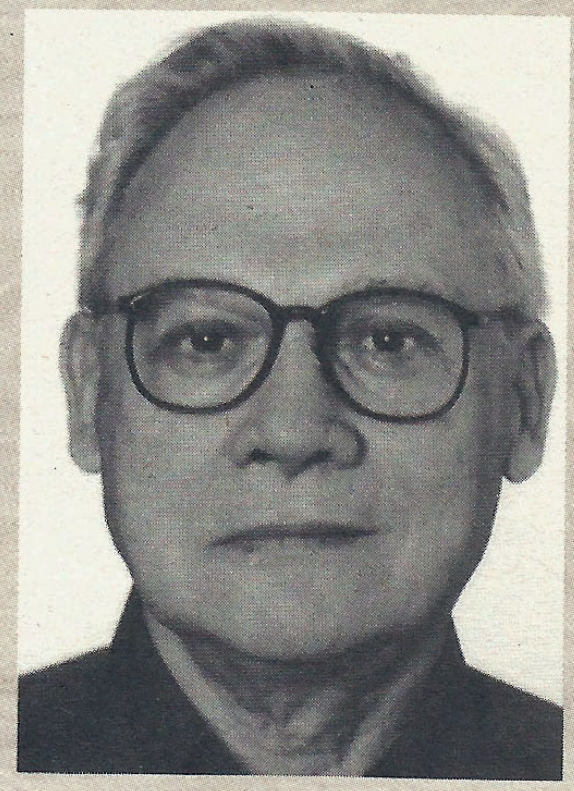

Dr. Zilton Andrade nasceu em 1924 na cidade de Santo Antônio de Jesus, na Bahia, onde fez apenas o curso primário. Completou a sua formação em Salvador, graduando-se em medicina na universidade Federal da Bahia (Ufba). A própria opção de estudar medicina foi motivada pelo fascínio pela ciência: começou a trabalhar em um laboratório de pesquisa quando era ainda estudante. Na ocasião, ingressou, por concurso, como técnico de laboratório num instituto de pesquisa fundado nos moldes do Instituto Oswaldo Cruz pelo Dr. Otávio Mangabeira Filho. Logo começou um curso de formação de pesquisadores, em 1949, no qual foi aluno do prof. Samuel Pessoa, uma influência definitiva para a sua formação. Sob a orientação do prof. samuel, participou pela primeira vez de uma pesquisa, relacionada à filariose; desenvolvida em Salvador, esta pesquisa representou não apenas vivência da metodologia científica, mas um modelo de dedicação, entusiasmo, seriedade e percepção ampla do que é a ciência e de que esta deve estar voltada para o benefício da população e para a resolução de problemas sociais. Segundo o Dr. Zilton, ele só não se tornou um parasitologista como o prof. samuel porque o laboratório onde estava necessitava de um patologista e, no convívio com o

${ }^{33}$ Dados extraídos da entrevista publicada em Cientistas do Brasil: depoimentos. São Paulo: SBPC, 1998:705-714. 
Dr. Paulo Dacorso Filho, vindo do Rio de Janeiro, descobriu e maravilhou-se com essa nova área. Após formar-se em medicina em 1950, foi para a Universidade de Tulane, em Nova Orleans, EUA, onde fez residência em patologia por dois anos, após os quais prosseguiu para o doutorado na Faculdade de Medicina de Ribeirão Preto. Voltando à Bahia em 1956, tornou-se chefe do serviço de patologia do Hospital das Clínicas Edgard Santos, da Faculdade de Medicina. Foi um dos fundadores dos primeiros laboratórios de pesquisa instalados na Bahia, destacando-se a sua liderança na criação do centro de Pesquisas Gonçalo Muniz, unidade da Fiocruz em Salvador, do qual foi o primeiro diretor, a partir de 1981. Integrou por dez anos o comitê de doenças parasitárias da OMS e vários comitês de agências de fomento ao desenvolvimento científico no Brasil. Até o presente ano já publicou mais de 250 trabalhos científicos e organizou livros amplamente utilizados por estudantes e pesquisadores em todo o país. 